\title{
Management Efficiency in Russian Super League Football Clubs in 2016 and 2017
}

\author{
Andrey Polozov, Liudmila Brekhova \\ Institute of Physical Culture, Sports and Youth Policy, Ural Federal University, Ekaterinburg, Russia
}

\section{Email address:}

A.A.Polozov@mail.ru (A. Polozov)

\section{To cite this article:}

Andrey Polozov, Liudmila Brekhova. Management Efficiency in Russian Super League Football Clubs in 2016 and 2017. American Journal of Sports Science. Vol. 6, No. 3, 2018, pp. 114-121. doi: 10.11648/j.ajss.20180603.17

Received: May 30, 2018; Accepted: June 8, 2018; Published: July 7, 2018

\begin{abstract}
The Russian Super League ranks sixth by its clubs' budgets while the Russian national team lags behind occupying the 60th place in the world rankings. Players' salaries do not correspond to their actual on-pitch performance. The problem may lie in the low level of football management efficiency, more specifically, in the 'pay-levelling' system in Russian football, which does not incentivize players to improve their performance but instead puts them in the same position as civil servants.
\end{abstract}

Keywords: Football, Players' Salaries, Management Efficiency, Ratings

\section{Introduction}

We accept the fact that the results demonstrated by Russian football clubs reflect the amount of funds invested in their development. At the time of writing this paper, football club 'Krasnodar' ranked 56th (www.ra-first.ru) by its performance and had a budget of 75 million dollars. 'CSKA' ranks 70th with the budget of 80 million dollars. In order to win, for example, the Euro Cup, these clubs should reach the level of 'Liverpool' with its budget of 440 million dollars. Obviously, the budgets of clubs from Russia and England can not be compared. Clubs with small budgets need to learn how to use their budget more effectively.

Another side of this question is a paradoxical situation when the Russian Super League ranks sixth by its clubs' budgets while the Russian national football team lags behind and occupies the 60th place in the world rankings. The question arises as to the cause of this paradox. It is particularly important to understand the reason for this situation since at the FIFA World Cup 2018. the Russian team will have to oppose thirty-two of the world's strongest teams.

Modern football is not only about sport, it is a huge business. The Fédération Internationale de Football Association (FIFA) with its 240 member states surpasses the UN in membership, the UN having only 191. The FIFA comprises over 300,000 clubs and approximately 240 million players. According to the Federation's reports, its annual revenue is 700 million dollars, $96 \%$ of which is event-related. While in 1984 companies paid the Federation 2 billion dollars for sponsporship, in 2006, it was already 16 billion. Football clubs also have a certain income but none of them can earn so much only by selling tickets. In Russia going to a game is considered as quite expensive while in Europe and America profits from ticket sales do not even cover the venue rental cost. Clubs make money primarily through advertising, merchandise sales, and by selling their players to other clubs $[2]$.

In the largest championships most of the revenue of the leading Italian, English, Spanish and German clubs is generated through advertising campaigns. The contract with the title sponsor, whose logo is put on payers' T-shirts, brings such organizations tens of millions of dollars while contracts with television companies for broadcasting games, hundreds of millions. Dutch and French clubs, which have not had any European triumphs for more than ten years, have been making money by selling their players. All this makes footballers' performance and their value crucial for their clubs' finance.

There are several famous programs for training in football club management. In 1995, the International Centre for Sports Studies (CIES) was created as a joint venture between the FIFA, the University of Neuchâtel, the City and State of Neuchatel. This centre is targeted at professionals in the 
sports market. Another example is the University of Liverpool, which offers an MBA course for young people interested in the football industry. One more similar MBA programme has been recently launched by Cass Business School, which ranked 47th among the world's best universities in 2006, according to the business school ranking from the Financial Times.

One of the crucial aspects for management of a top-level football club is the relationship of the three key figures: the investor, the club's president and the coach. At first sight, this might seem as a linear relationship: the president reports to the investor and the coach to the president. This relationship, however, is much more complex: according to Milan Tomic, who was the manager of 'Crvena Zvezda' (also known as 'Red Star Belgrade'), power in a sports club is usually decentralized. In his book 'Basics of Sports Management' he refers to this phenomenon as 'adhocracy' [8]. Tomic describes the situations when there was no strict division of responsibilities between the managers of the club, which did not prevent the club comprising twenty teams from achieving enormous success in Yugoslavian football. Thus, we can conclude that the main weakness of sports club management is that it fails to achieve a balance between the sport-related and financial sides of any decision making. This aspect, however, is not included in any of the above-mentioned training programs.

Most of the works about rating methods in sport focus on clubs. For instance, the following on-line resources deal with the finance of football clubs: Swiss Ramble, ander sred blog, Footballeconomy.com, Forbes Sports Money [9]. In his work, Scelles discusses the factors that shaped the development of sport in the period between 2004 and 2011.

Such consulting companies as Deloitte and Brand Finance conduct regular studies of football clubs' financial performance. The investment analytics of JP Morgan, Gran Thornton and Jefferies can be used as a basis for designing a rating model of football organizations. CIES Football Observatory and transfermarkt.de study transfer value of football players. Many American researchers seek to find a correlation between sports and business activities of professional clubs [10-12].

The questions of value assessment of sports clubs are discussed separately. For example, Markham [16] developed his own original model to evaluate sports clubs, which included a variety of approaches such as the evaluation of certain clubs' revenues and expenditures and comparing them to those of other clubs. In [15] analysed income and expenses of teams, measured the level of risk for sport investors and proposed a general model for the evaluation of the Los Angeles Clippers. Scelles, Helleu, Durand and Bonnal (2015) analyzed determinants of team values, compared American and European teams and proposed to incorporate the number of fans and followers on social media and player values in value models $[11,12]$.

In general, it should be noted that there is a large literature on efficiency and its assessment but few studies address the question of efficiency in sports industry. Among such studies, we must mention Chelladurai and Haggerty's, who applied the model of organizational effectiveness of Canadian national sport organizations [17]. A similar study of Greek sport was conducted by Papadimitriou and Taylor [18]. Wolfe, Hoeberb and Babiak have identified the factors that determine efficiency in student sports and have found out how these factors interact [20].

This study assesses the correlation between the professional excellence of football players in the 2016-2017 Russian Super League and the level of their salaries.

Thus, this study pursues the following objectives:

Firstly, to describe the methodology of building the most accurate and reliable rating scales of footballers;

Secondly, to analyze the correlation between the on-field and financial performance of clubs by using the case of the Russian Football Super League in 2016 and 2017;

Finally, assess the work of the coach on the balance of financial and sports results of the club

Theoretical framework

In football, a team is normally assessed by the number of completed technical and tactical actions (TTAs), the percentage of mistaken actions, and the distance the players run with maximal and submaximal energy. In 1986, Godik calculated that the coefficient of correlation between TTAs and the results of matches played by the team's closest rivals was about 0.2 (1) in football. In basketball this coefficient is 0.34 , which means that the situation is not too different (2). Therefore, the coach's expert assessment becomes important since its correlation with the results of matches can even exceed 0.6. Nevertheless, the potential of the coach's assessment is also limited. The main problem is that in football there is too much information to be processed by one person. A coach cannot predict how his team should perform in an ordinary match in order to, for instance, win the UEFA Cup; he needs IT-assistance to do that. Sergei Skorovich, the coach of the Russian national mini-football team, engaged this author to assess his team, which led to changes in the team's composition and thus enabled it to achieve success.

\section{Method}

This author has created methodology for assessment of teams and players, which will be briefly described further (for more detailed description see [1, 3-7] or www.rafirst.com).

Technical and tactical confrontations:

i. There are sixty different types of technical and tactical confrontations such as back-pass, ball control, aerial confrontations, groundmoves, and so on.

ii. Players realize scoring opportunities through heading, from the left or from the right or from a non-standard position.

Value of confrontations

i. The value of winning a confrontation is equal to gained chances of scoring a goal from the end point in relation to the initial point on the football pitch.

ii. The total value of all the confrontations won and lost 
by a specific player is a part of the difference created by the team.

iii. If we calculate the value of confrontations, it will improve the accuracy of the coefficient of correlation with games results from 0.2 to $0.8-0.9$, which allows us to get rid of the information noise.

Tactics

i. Tactics in football implies redistribution of pressure to benefit stronger players, who are pitted against weaker opponents (in the same game component).

ii. A player creates a difference through tactics, for example, by maximizing the competitive advantage they gain from favourable 'exchanges'. ('Exchange' is a term used by football coaches about the situations when specific players of one team are pitted in such a way that they oppose specific players of the rival team. 'Exchanges' refer to pairs these two teams are thus split in). Therefore, the difference is equal to the product of the player's advantage in the game component by the number of such confrontations.

Rating

i. All the results of the team or specific players in different games are converted into ratings, which allow us to assess their performance more accurately.

ii. The rating of a player and/or a team is automatically projected on an abstract average participant of this tournament.

iii. The rating has a linear connection with the difference thus created. A 400-point difference in the rating of two teams corresponds to the game's score 7:3 (the advantage of 4 goals with 10 as the total sum of goals scored and missed).

iv. The algorithm of rating calculation and the structure of linear equations help us establish correspondence between the expected and actual results.

v. The existing FIFA/Coca-Cola Ranking is misleading since its calculation procedure results in disparity between the generally perceived quality and the world ranking of some teams. Thus, at all European and world championships teams with lower positions in the ranking defeat those with higher positions. Weaker teams are satisfied with such situation since it gives them extra opportunities for forming the so-called 'groups of death' for stronger teams and so on. This stalemate situation which results from leaders always being in the minority. Football has thus fallen victim to its own popularity.

vi. The coach's ranking depends on the team's position in financial and sport rankings.

Player's rating

i. corresponds to the rating of the team consisting of such players;

ii. corresponds to the correlation between the value of the won and lost confrontations during the match and the average opponent in this tournament;

iii. falls exponentially during the match from the number of confrontations with the different speed of various components.

Data and methodology In order to calculate the ranking, we need to solve a system of linear equations:

$$
\left\{\begin{array}{l}
R t_{I}=\sum_{\frac{J=1}{I \neq J}}^{N} \delta_{J} \times R t_{J c o p}+\Delta_{I} \\
R t_{\text {С Р Е д }}=\left(\frac{1}{\mathrm{n}}\right) \times \sum_{\mathrm{I}=1}^{\mathrm{n}} \mathrm{Rt}_{\mathrm{I}}
\end{array}\right.
$$

Let us use the following hypothetical competition as an example:

Table 1. Hypothetical competition.

\begin{tabular}{llllll}
\hline Team & $\mathbf{1}$ & $\mathbf{2}$ & $\mathbf{3}$ & Scored and missed goals & Rt \\
\hline A & & $6: 4$ & $7: 3$ & $13: 7$ & 2200 \\
B & $4: 6$ & & $6: 4$ & $10: 10$ & 2000 \\
C & $3: 7$ & $4: 6$ & & $7: 13$ & 1800 \\
\hline
\end{tabular}

Result: Rt $(A)=2200$; Rt $(B)=2000$ : Rt $(C)=1800$. Let us now check our solution. A defeated B with the score $6: 4$, which results in 200 points. The corresponding difference is $2,200-2,000$. A defeated C 7:3, which results in 400 points. The corresponding difference is $2,200-1,800$.

$$
\left\{\begin{array}{c}
\operatorname{Rt}(A)=\left(\frac{6+4}{13+7}\right) \times \operatorname{Rt}(B)+\left(\frac{7+3}{13+7}\right) \times \operatorname{Rt}(C)+\frac{13-7}{13+7} \times 1000 \\
\operatorname{Rt}(B)=\left(\frac{6+4}{10+10}\right) \times \operatorname{Rt}(A)+\left(\frac{4-6}{10+10}\right) \times \operatorname{Rt}(C)+\frac{10-10}{10+10} \times 1000 \\
\operatorname{Rt}(C)=\left(\frac{7+3}{7+13}\right) \times \operatorname{Rt}(A)+\left(\frac{6+4}{7+13}\right) \times \operatorname{Rt}(B)+\frac{7-13}{7+13} \times 1000 \\
(\operatorname{Rt}(A)+\operatorname{Rt}(B)+\operatorname{Rt}(C)) / 3=2000
\end{array}\right.
$$

\section{Result}

Experiment description

We observed matches of the ninth round of the Russian Super League on 2.10.2016. After processing the video data, we calculated ratings for all 204 players of the Russian Super
League who participated in the matches. The advantage of Player A over Player B in the rating means the difference in the number of goals scored and missed during the match played between the teams consisting of Players A and B.

What interests us is how much this assessment of a player can vary in different matches (see Table 1). 
Table 2. Variability of values of 'CSKA' and 'Krasnodar' players' performance in the match of the Super League and the European Cup tournament (round 9 , Russian Championship, 2016).

\begin{tabular}{llllllll}
\hline & 'CSKA' & 'Rostov' & 'Tottenham' & & 'Krasnodar' & 'Schalke' & 'Rubin' \\
\hline 9 & Traoré & 2957 & 3141 & 6 & Granqvist & 2597 & 2426 \\
24 & V. Berezutski & 2941 & 2901 & 9 & Ari & 2459 & 2253 \\
4 & Ignashevich & 2783 & 3231 & 8 & Gazinsky & 2449 & 2137 \\
25 & Eremenko & 2650 & 2701 & 11 & Podberezkin & 2353 & 2336 \\
17 & Golovin & 2601 & 2808 & 98 & Petrov & 2283 & 2027 \\
66 & Natkho & 2586 & 2664 & 55 & Jędrzejczyk & 2199 & 2399 \\
8 & Milanov & 2515 & 2509 & 22 & Joãozinho & 2186 & 2223 \\
& & & & Kaboré & 2153 & 2439 \\
7 & Tošić & 3032 & 2477 & 38 & Kouassi & 2145 & 1996 \\
42 & Shchennikov & 2320 & 2880 & & & & \\
2 & Fernandes & 2316 & 3014 & & & & \\
\hline
\end{tabular}

We can see that for sixteen players of 'CSKA' and 'Krasnodar' the rating is relatively stable while only the rating of three players of 'CSKA' has demonstrated significant fluctuations in their performance. Two of these players were reported to have been injured.

Now let us analyze the Super League players' salaries.

Table 3. Real and recommended salaries of Super League players.

\begin{tabular}{|c|c|c|c|c|c|c|c|}
\hline & Ranking & Salary, mln dollars & № & Name & Club & $\begin{array}{l}\text { Russian salary } \\
\text { trends, mln dollars }\end{array}$ & $\begin{array}{l}\text { Global salary } \\
\text { trends, mln dollars }\end{array}$ \\
\hline 1 & 3273 & & 7 & Ananidze & Spartak & 2.63 & 9.36 \\
\hline 2 & 3032 & 1.6 & 7 & Tošić & CSKA & 2.55 & 7.80 \\
\hline 3 & 3028 & & 33 & Maurício & Spartak & 2.55 & 7.77 \\
\hline 4 & 3006 & & 23 & Mevlja & Rostov & 2.54 & 7.63 \\
\hline 5 & 2991 & 2.7 & 16 & Bocchetti & Spartak & 2.54 & 7.53 \\
\hline 6 & 2957 & & 9 & Traoré & CSKA & 2.53 & 7.31 \\
\hline 7 & 2955 & 3.0 & 8 & Glushakov & Spartak & 2.53 & 7.30 \\
\hline 8 & 2948 & 2.2 & 4 & Criscito & Zenit & 2.53 & 7.25 \\
\hline 9 & 2948 & & 44 & Navas & Rostov & 2.53 & 7.25 \\
\hline 10 & 2947 & & 18 & Kutepov & Spartak & 2.53 & 7.24 \\
\hline 11 & 2941 & & 47 & Zobnin & Spartak & 2.52 & 7.20 \\
\hline 12 & 2941 & 1.9 & 24 & V. Berezutski & CSKA & 2.52 & 7.20 \\
\hline 13 & 2932 & 1.4 & 3 & Wernbloom & CSKA & 2.52 & 7.14 \\
\hline 14 & 2892 & 4.5 & 21 & García & Zenit & 2.51 & 6.89 \\
\hline 15 & 2892 & & 5 & Vasin & Ufa & 2.51 & 6.88 \\
\hline 16 & 2886 & & 7 & Giuliano & Zenit & 2.51 & 6.85 \\
\hline 17 & 2878 & & 16 & Noboa & Rostov & 2.50 & 6.79 \\
\hline 18 & 2859 & 2.2 & 19 & Smolnikov & Zenit & 2.50 & 6.67 \\
\hline 19 & 2846 & & 8 & Maurício & Zenit & 2.49 & 6.59 \\
\hline 20 & 2823 & & 84 & Gaţcan & Rostov & 2.48 & 6.43 \\
\hline 21 & 2819 & 1.6 & 4 & Granat & Rostov & 2.48 & 6.41 \\
\hline 22 & 2808 & & 9 & Zé Luís & Spartak & 2.48 & 6.34 \\
\hline 23 & 2783 & 2.0 & 4 & Ignashevich & CSKA & 2.47 & 6.17 \\
\hline 24 & 2742 & 5.0 & 9 & Kokorin & Zenit & 2.46 & 5.91 \\
\hline 25 & 2736 & 2.0 & 13 & Neto & Zenit & 2.46 & 5.87 \\
\hline 26 & 2714 & & 6 & Nadson & Krylya Sovetov & 2.45 & 5.73 \\
\hline 27 & 2685 & 3.6 & 22 & Dzyuba & Zenit & 2.44 & 5.54 \\
\hline 28 & 2683 & & 77 & Tigiev & Anzhi & 2.44 & 5.53 \\
\hline 29 & 2663 & 2.0 & 14 & Yusupov & Zenit & 2.43 & 5.39 \\
\hline$\ldots \ldots$ & $\ldots \ldots$. & ........ & & $\ldots \ldots$ & ......... & $\ldots \ldots$ & \\
\hline 211 & 1287 & & 13 & Nekhaychik & Orenburg & 1.98 & -3.56 \\
\hline 212 & 1119 & & 3 & Yatchenko & Krylia Sovetov & 1.92 & -4.66 \\
\hline 213 & 1066 & & 55 & Yanbaev & Lokomotiv & 1.90 & -5.00 \\
\hline
\end{tabular}

These thirty-four pairs of results have allowed us to draw the following formula:

Salary $=1,558+0.000331 \times \mathrm{Rt}$ 
We applied this formula to calculate the expected salaries (this result is given in the last but one column of the table). In this case, the total sum of the annual payments made to players of the Super League would be 482 million dollars. This figure, however, does not correspond to the global trend of the correlation between the player's salary and their actual performance.

In 2015, 'Sportingintelligence' (http://www.globalsportssalaries.com/) published the average value of players of 32 national teams taking part in the final matches of the 2014 FIFA World Cup in Brazil. Analyzing these data, we can observe a correlation between the growth in players' salaries and their field performance and to rank the teams in descending order according to how undervalued their players are.

Table 4. Players' performance and salaries at the 2014 FIFA World Cup.

\begin{tabular}{|c|c|c|c|c|c|}
\hline & Country & $\begin{array}{l}\text { Undervaluation } \\
\text { of players }\end{array}$ & $\begin{array}{l}\text { Average salary in the } \\
\text { national team of } 2014\end{array}$ & $\begin{array}{l}\text { Rating of the national team in } \\
\text { the period } 2010-2014\end{array}$ & $\begin{array}{l}\text { Average expected salary depending } \\
\text { on the team's performance }\end{array}$ \\
\hline 1 & Colombia & 2.80966 & 0.93 & 3066 & 3.73966 \\
\hline 2 & Chile & 2.28456 & 1.39 & 3056 & 3.67456 \\
\hline 3 & Ecuador & 1.58927 & 0.92 & 2877 & 2.50927 \\
\hline 4 & Bosnia & 1.41759 & 1.3 & 2909 & 2.71759 \\
\hline 5 & Holland & 1.25905 & 3.06 & 3155 & 4.31905 \\
\hline 6 & Algeria & 1.21941 & 0.73 & 2791 & 1.94941 \\
\hline 7 & Mexico & 1.08424 & 1.08 & 2824 & 2.16424 \\
\hline 8 & Switzerland & 0.95484 & 1.6 & 2884 & 2.55484 \\
\hline 9 & Russia & 0.89624 & 2.57 & 3024 & 3.46624 \\
\hline 10 & Costa Rica & 0.84633 & 0.4 & 2683 & 1.24633 \\
\hline 11 & Greece & 0.83411 & 0.92 & 2761 & 1.75411 \\
\hline 12 & Iran & 0.82123 & 0.36 & 2673 & 1.18123 \\
\hline 13 & Australia & 0.56888 & 0.71 & 2688 & 1.27888 \\
\hline 15 & Ghana & 0.23478 & 1.63 & 2778 & 1.86478 \\
\hline 16 & Nigeria & 0.17183 & 1.4 & 2733 & 1.57183 \\
\hline 17 & USA & -0.07676 & 1.59 & 2724 & 1.51324 \\
\hline 18 & Croatia & -0.21925 & 2.39 & 2825 & 2.17075 \\
\hline 19 & Brazil & -0.32727 & 5.74 & 3323 & 5.41273 \\
\hline 20 & Honduras & -0.36225 & 0.58 & 2525 & 0.21775 \\
\hline 21 & Uruguay & -0.3712 & 2.9 & 2880 & 2.5288: \\
\hline 22: & Cote d'Ivoire & -0.54804 & 2.53 & 2796 & 1.98196 \\
\hline 23 & Argentina & -0.62759 & 4.53 & 3091 & 3.90241 \\
\hline 24 & Italy & -0.63945 & 2.68 & 2805 & 2.04055 \\
\hline 25 & France & -0.85846 & 4.52 & 3054 & 3.66154 \\
\hline 26 & Portugal & -0.8804 & 3.93 & 2960 & 3.0496 \\
\hline 27 & North Korea & -0.89 & 0.89 & 2321 & 0 \\
\hline 30 & Germany & -2.03404 & 6.62 & 3196 & 4.58596 \\
\hline 31 & Spain & -2.76699 & 7.06 & 3151 & 4.29301 \\
\hline 32 & England & -2.81718 & 6.01 & 2982 & 3.19282 \\
\hline
\end{tabular}

Table 3 shows that the most undervalued footballers play in the Colombian team while the most overvalued ones, in the English one, which reveals the difference in the economies of these two countries.

Table 3 also illustrates that on average a gain of 100 ranking points brings a salary increase of $0.651 \mathrm{mln}$ dollars (we can find all the available data on football clubs' budgets on the web-site www.ra-first.ru). The general trend is that every budget increase of one million dollars corresponds to a gain in seventeen ranking points in the annual ranking. One of the eleven team players can increase the team's ranking by seventeen points if he is $11 \times 17=187$ points stronger. For a 100 -point increase the club can offer him 0.535 million dollars. The figures 0.535 and 0.651 are quite close to each other.

Let us calculate the salaries of Super League football players on the basis of the above-described global trend (see the last column of Table 2). The result is really surprising. In the interval between 176 and 213, the salary values become negative, that is, 38 players of the Super League would actually have to pay their teams for the right to play. If we add these negative values, we will get a figure close to that of the total spending on all players' wages - 492 million dollars.

\section{Discussion}

In Russia, sponsors of a football team are often companies of the oil and gas, materials and banking sectors. These 
companies do not willingly choose to become sponsors - they often have to make a 'socially significant contribution', that is, support football teams in exchange for government contracts. In this situation, sponsors consider their invested funds as unavoidable expenses and do not care about their profitability. This is what engenders corruption.

There is no objective, impartial assessment of players and teams in Russian football since the level of a player's excellence is usually assessed by the club's coach or president. This is when the player's agent enters the game. Unfortunately, the FIFA and the Russian Football Union have made a number of substantial errors. Attempts were made to eliminate agents from this process on the grounds that they stimulate corruption: for instance, an agent might try to bribe the coach to set a high transfer cost for the player. In a similar way, an agent might approach the coach of the national team. In team sports, the value of a contract of a national team player is approximately $25 \%$ higher than that of an ordinary footballer, which means that we are likely to see a group of players whose level does not conform to the Super League level. The rating of a player equals the rating of a team consisting of such players. A team can gain an advantage of 1,000 points over its opponent only when one team scores as many goals as they want and never misses a ball. If all players of this team are weaker than their opponents, nothing will save the team from losing this game. The tactical struggle starts only when there are several players who are better than some players of the opposing team. To achieve this, players must 'fit' within the 1,000-point interval. The difference between the performance of a leader and that of an outsider among the Russian Super League players is 2,100 points. In the 1000-point interval there are 98 players of the Super League ( 9 teams) and the ones who do not fit into this interval are uncompetitive. Thus, 38 players out of 204 have demonstrated nothing to be paid for. Naturally, such situation can be caused by other factors: players might be recovering from injuries, be stressed or overworked, and so on. We cannot draw any firm conclusions by using fragmentary data such as salaries or accuse the agents of corruption if their players have failed to make the most of their abilities. What we need is to solve the problem, not blame the agents.

In 2016, the 'CSKA' coach Leonid Slutsky resigned on his own accord after winning seven trophies in seven years of work. The journal 'Theory and Practice of Physical Culture' published a paper on the methods of assessment of the coach's efficiency by analyzing the financial and sportrelated aspects of the club's work (see website ra-first.com). On this website we have created an information service to monitor the top football clubs' performance. The parser reads the data on football clubs' results and calculates their ratings by solving the above-mentioned system of linear equations. This information can be supplemented with the data on the club's budget for the following season. Basically, the efficiency of the club's management is assessed by building a direct correlation between the budget and the rating. Then, we calculate the club's expected rating by taking into account the club's budget and compare the result with the actual rating. We can judge about the efficiency of the club's management if a club with a small budget can win a higher position in the table. Most of this dividend is brought by the coach of the club.

Table 5. Efficiency of head coaches (data as of 12. 2016).

\begin{tabular}{|c|c|c|c|c|c|c|}
\hline Position & Efficiency & Name & Rt sport & Rt finance & Club & Budget, mln dollars \\
\hline 44 & 268 & Kononov O. & 3174 & 2906 & Krasnodar & 75 \\
\hline 88 & 177 & Slutsky L. & 3092 & 2916 & CSKA & 80 \\
\hline 98 & 165 & Lucescu M. & 3280 & 3115 & Zenit & 185 \\
\hline 139 & 71 & Cherevchenko I. & 3006 & 2935 & Lokomotiv & 90 \\
\hline 162 & 26 & Rakhimov R. & 2846 & 2821 & Terek & 30 \\
\hline 168 & 14 & Gadzhiyev G. & 2803 & 2788 & Amkar & 13 \\
\hline
\end{tabular}

Table 6. Leading KHL coaches in 2015.

\begin{tabular}{llll}
\hline Effect & KHL coaches & Club & Year of birth \\
\hline 166 & Pēteris Skudra & Torpedo & 1973 \\
155 & Artis Ābols & Dinamo Riga & 1973 \\
139 & Andrey Nazarov & Donbass & 1974 \\
126 & Mark French & Medveshchak & 1971 \\
125 & Kari Jalonen & Lev & 1960 \\
123 & Anatoly Emelin & Avtomobilist & 1964 \\
117 & Oleg Znarok & Dynamo Moscow & 1963 \\
109 & Sergey Svetlov & Admiral & 1961 \\
98 & Ari-Pekka Selin & Barys & 1963 \\
78 & Dmitry Kvartalnov & Sibir & 1966 \\
67 & Michael E. Keenan & Metallurg & 1949 \\
55 & Jukka Jalonen & CSKA & 1962 \\
\hline
\end{tabular}

It would be interesting to know how 'CSKA' management is planning to reach the Champion's League after replacing a more efficient coach with a less efficient one (a similar situation has occurred to 'Krasnodar').

Figure 1 shows the correlation between the age and performance of 204 Russian Super League players. There used to be an assumption that the player's performance peaks at the age of 25 (2). The graph clearly shows, however, that there are actually two peaks - at the age of 24 and 28. It is known that in sprint, records are rarely renewed after 24 , in long-distance running, after 28. Therefore, we can suppose that these two peaks are related to the qualities most required for both of these physical activities. Players' salaries can also be expected to reflect this dynamics. 


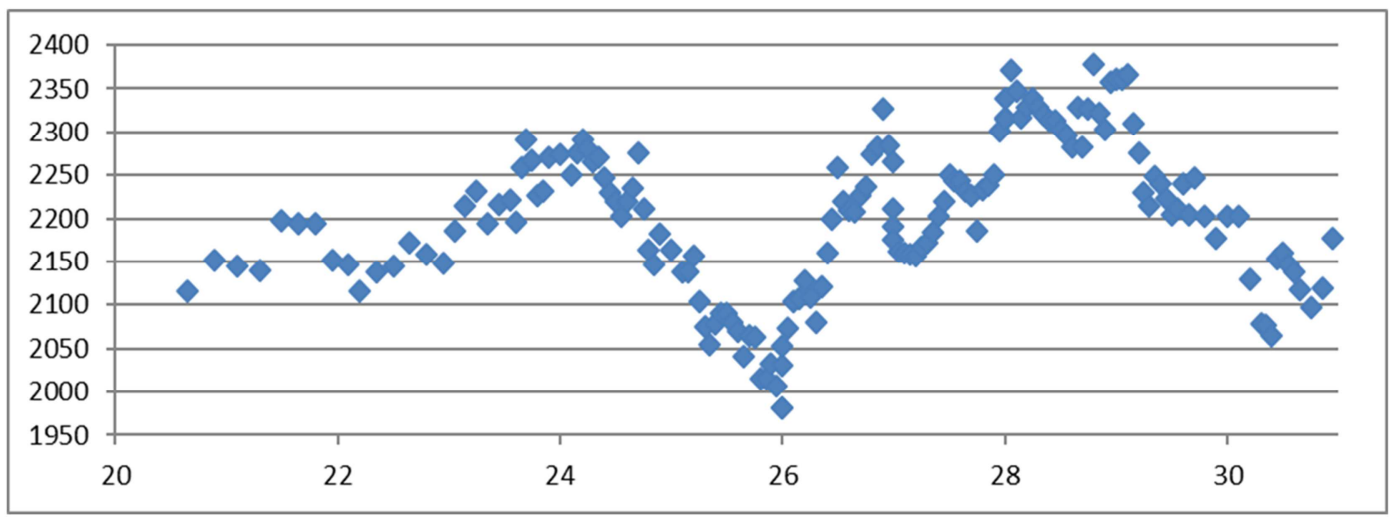

Figure 1. Correlation between the rating (y) Russian Super League players' performance and their age (x).

\section{Conclusion}

1. According to the available data, the coefficient of correlation between the Russian Super League players' average salaries and their on-field performance is 0.138 . Thus, we are dealing with a 'pay levelling' trend, which does not affect, however, some leaders of the national team. In Russia, there is no proper football management. Footballers do not seek contracts with overseas clubs and instead turn into a kind of civil servants paid just because they occupy their work places.

2. At the moment government regulation dominates in the sports sphere, while the government should, on the contrary, avoid interfering in sports. Investors should encourage and support independent assessment of players.

3. Football is funded by sponsors, not the Russian Football Union. Therefore, the Union's objective should be to attract more investments to football and to help football clubs use them efficiently. It is recommended that the Russian Football Union should assess its own efficiency by the number of players participating in the five leading championships (England, Spain, Italy, Germany and France). It is also recommended to stimulate the exchange of teams between the leagues and abolish the so-called 'legionnaires' quota', that is, the limit on the number of foreign footballers playing for Russian football clubs.

4. Agents should be orientated more towards working with Latin American players rather than African players.

5. Club presidents should be choosing coaches by applying a balanced approach and assessing both the team's on-field performance and its financial situation.

\section{References}

[1] Innovative System of Assessment of Efficiency of Basketball Players/ Burov I. V., Polozov A. A./ World of Scientific Discoveries, № 9.1 (21) 2011. Science and Education. P.363. ISSN 2072-0831.

[2] Panoyan A. Nineteen Billion in One Gate// RosBusinessConsulting: online journal. 2012. [Electronic resource]. URL:http://www/rbc.ru (last accessed date:
24.12.2012).

[3] Polozov A. A. Ranking in Sports: Yesterday, Today, Tomorrow. - Moscow: Sovetsky Sport, 2007. - 316 p.

[4] Optimal Composition of the Russian National Team for the 2018 FIFA World Cup as of 10.2016/ Polozov A. A. /Theory and Practice of Physical Culture, 2017, № ?, P.?

[5] Handbook of Ratings. Approaches to Ratings in the Economy, Sports, and Society/ A. Karminsky, A. Polozov/ International Publishing house "Springer", 2016., 360c.

[6] Polozov A. A. Tactical Effect//Theory and Practice of Physical Culture. 2002. №6. P. 55.

[7] Age-related Career Peaks of a Sports Judge and Coach/ A. A. Polozov [et al.] //Theory and Practice of Physical Culture. 2016. № 1. P. 80.

[8] Tomić M. Basics of Sports Management. - Moscow: International Academy of Football and Sports Industry, 2005. $-152 p$.

[9] Reade, I., Rodgers, W., Norman L. (2015). The UnderRepresentation of Women in Coaching: A Comparison of Male and Female Canadian Coaches at Low and High Levels of Coaching. International Journal of Sports Science and Coaching, 4,4 .

[10] http://www.globalsportssalaries.com/.

[11] Scelles, N., Helleu, B., Durand, C., Bonnal, L. (2014). Professional Sports Firm Values: Bringing New Determinants to the Foreground? A Study of European Soccer, 2005-2013. Journal of Sports Economics, 1-28.

[12] Scelles, N., Helleu, B., Durand, C., Bonnal, L. (2013). Determinants of Professional Sports Firm Values in the United States and Europe: A Comparison Between Sports over the Period 2004-2011. International Journal of Sport Finance, 8, 280-293/.

[13] Alexander, D. L. \& Kern W. (2004). The economic determinants of professional sports franchise values. Journal of Sports Economics, 5 (1), 51-66.

[14] Rodney Fort, The Value of Major League Baseball Ownership, International Journal of Sport Finance, 2006, 1, 920, (C) 2006 West Virginia University.

[15] Miller P. A., Private financing and sports franchise values: The case of major league baseball. Journal of Sports Economics, 8 (5), 2007 p. 449-467. 
[16] Markhman, T. (2013). What is the optimal method to value a football club? ICMA Centre, Henley Business School, University of Reading, Retrieved from http://papers.ssrn.com/sol3/papers.cfm?abstract_id=2238265.

[17] Chelladurai P, Haggerty TR, Measures of organizational effectiveness of Canadian national sport organizations, Canadian Journal of Sport Sciences, 1991, 16 ((2):126-133.

[18] Dimitra Papadimitriou1, Peter Taylor, Organisational Effectiveness of Hellenic National Sports Organisations: A Multiple Constituency Approach, Sport Management Review, Volume 3, Issue 1, May 2000, Pages 23-46.
[19] Angela Koh-Tan, The determinants of effectiveness of sporting associations in Singapore, Managing Leisure Volume 16, Issue 3, 2011, c. 7-10.

[20] Richard Wolfe, Larena Hoeberb \& Kathy Babiak, Perceptions of the effectiveness of sport organisations: The case of intercollegiate athletics. European Sport Management Quarterly Volume 2, Issue 2, 2002, c. 44-49.

[21] O'Boyle, I. (2015). Developing a performance management framework for a national sport organization. Sport Management Review, 18, 308-316. 